\title{
Deproteinization stabilises dentin bonding of self-adhesive resin cements after thermocycling
}

\author{
Lidiane Costa de Souza ${ }^{a}$, Nara Sousa Rodrigues ${ }^{a}$, Victor Pinheiro Feitosa ${ }^{\text {b }}$, \\ Issis Virgínia Luque-Martinez ${ }^{\mathrm{c}}$, Alessandro Dourado Loguercio ${ }^{\mathrm{d}}$, \\ Vicente de Paulo Aragão Saboia ${ }^{\mathrm{b}, *}$ \\ a Graduate Program of Dentistry Faculty of Pharmacy, Dentistry and Nursing, Federal University of Ceará, Fortaleza, Ceará, Brazil \\ ${ }^{\mathrm{b}}$ Department of Restorative Dentistry School of Dentistry Faculty of Pharmacy, Dentistry and Nursing, Federal University of Ceará, Fortaleza, Ceará, Brazil \\ ' Department of Operative Dentistry, State University of Ponta Grossa, Paraná, Brazil \\ d Department of Restorative Dentistry, Restorative Dentistry, State University of Ponta Grossa, Paraná, Brazil
}

\section{A R T I C L E I N F O}

Article history:

Accepted 14 November 2015

Available online 18 December 2015

Keywords:

Adhesion

Dentine

Nanoleakage

Sodium hypochlorite

Surface treatment

\begin{abstract}
A B S T R A C T
This study examined the effect of deproteinization on the microtensile dentin bond strength ( $\mu \mathrm{TBS}$ ) and nanoleakage $(\mathrm{NL})$ of conventional and self-adhesive resin cements after $24 \mathrm{~h}$ or after 20,000 thermocycles. Occlusal dentin of thirty-two human molars were distributed into four groups according to the type of cement used: conventional or self-adhesive; and the strategy of luting: RelyX ARC/Single Bond 2 (RAc) following the manufacturer's instructions (control), RelyX ARC/Single Bond 2 (RAd) applied after dentin deproteinization; RelyX U200 (RUc) following the manufacturer's instructions (control); RelyX U200 (RUd) applied after dentin deproteinization. The specimens were cut into non-trimmed dentincomposite sticks and the half sticks of each group were subdivided into two subgroups: $24 \mathrm{~h}$ water storage and after 20,000 thermal cycles, before microtensile bond test. For NL, 5 bonded sticks from each subgroup were prepared and analyzed under SEM. Three-way ANOVA showed that the dentin deproteinization increased the $\mu$ TBS of both cements, although the RAd group showed a decrease on the $\mu$ TBS after thermocycling. Chi-square test showed significant loss of specimens by premature failure for the groups after thermocycling, except for the RUd group. The dentin deproteinization improved the initial $\mu \mathrm{TBS}$ and decreases the NL of both cements tested, but, after thermocycling, this technique is only effective for RelyX U200.
\end{abstract}

(c) 2015 Elsevier Ltd. All rights reserved.

\section{Introduction}

Currently, resin cements are the most indicated luting materials in the cementation of indirect composite resins and ceramic restorations to tooth structures. These cements showed advantageous properties like low water sorption, low solubility and high color stability [1], bond to enamel and dentin [2] and dual-curing mode [3-5]. These cements have been widely used for fixation of inlays, onlays, crowns, posts, and veneers [6] because of their

\footnotetext{
* Correspondence to: Department of Restorative Dentistry - Faculty of Pharmacy, Dentistry and Nursing, Federal University of Ceará, R. Gilberto Studart, 770/901, Cocó, Fortaleza, CE 60190-750, Brazil . Tel: +55 8588074623.

E-mail addresses: lidiane.csouza@yahoo.com.br (L.C.d. Souza), nara.sousa.rodrigues@gmail.com (N.S. Rodrigues), victorpfeitosa@hotmail.com (V.P. Feitosa), issis31@hotmail.com (I.V. Luque-Martinez), aloguercio@hotmail.com (A.D. Loguercio),vpsaboia@yahoo.com (V.d.P.A. Saboia).
}

enhanced mechanical properties, ease of handling and good esthetic qualities [3].

These luting systems may be classified as conventional resin cements or self-adhesive resin cements, depending on the bonding strategies [7-9]. The conventional resin cement requires the previous application of adhesive systems, that can be an etch-andrinse or a self-etch system, while the self-adhesive cements requires no pretreatment of tooth surfaces [6,10-12]. Despite this attractive concept for cementation, scientific evidence has shown low retentive power of this cementation strategy for indirect restorations [13-15] and the superficiality of the interaction between the cement and dentin are the critical points in this new approach for self-adhesive cements $[6,7,15]$. Researches investigating pretreatment of dentin with acid solutions show controversial results.

Some studies have reported that the removal of the smear layer improved the interaction between self-adhesive resin cement and dentin [16-18]. On the other side, it has been shown that the 
Table 1

Resin cements, their application protocols and strategy of cementation.

\begin{tabular}{|c|c|c|c|}
\hline & Composition & Control & Deproteinized \\
\hline \multirow[t]{9}{*}{$\begin{array}{l}\text { RelyX ARC/Single Bond } 2 \\
\text { (3M/ESPE, Seefeld, } \\
\text { Germany) }\end{array}$} & \multirow[t]{3}{*}{$\begin{array}{l}\text { RelyX }{ }^{\text {MR }} \text { ARC: TEGDMA, Bis-GMA, ether zircônia/ sílica filler, } \\
\text { functional dimethacrylate polymer }\end{array}$} & $\begin{array}{l}\text { 1. Apply of } 37 \% \mathrm{H}_{3} \mathrm{PO}_{4} \text { Gel (Con- } \\
\text { dac } 37 \% / \mathrm{FGM} \text {, Joinville, SC, Brazil) } \\
\text { for } 15 \mathrm{~s}\end{array}$ & $\begin{array}{l}\text { 1. Apply } 37 \% \mathrm{H}_{3} \mathrm{PO}_{4} \mathrm{Gel} \text { (Condac } 37 \% / \\
\text { FGM, Joinville, SC, Brazil) for } 15 \mathrm{~s}\end{array}$ \\
\hline & & 2. Rinsing with air spray & $\begin{array}{l}\text { 2. Rinsing with air spray }+ \text { apply } 5 \% \\
\mathrm{NaOCl} \text { (Vetec, Rio de Janeiro, RJ, Bra- } \\
\text { zil) for } 2 \mathrm{~min}\end{array}$ \\
\hline & & $\begin{array}{l}\text { 3. Dry with absorbent paper, } \\
\text { keeping dentin moisture }\end{array}$ & 3. Rinsing with air spray for $30 \mathrm{~s}$ \\
\hline & \multirow[t]{6}{*}{$\begin{array}{l}\text { Adper Single BondTM 2: Ethanol, Bis-GMA, silanated silica filler, } \\
\text { 2-HEMA, GDM, copolymer of polyacrylic and polyitaconic } \\
\text { acidse UDMA. }\end{array}$} & $\begin{array}{l}\text { 4. Apply of two consecutive coats } \\
\text { of Single Bond } 2 \text { for } 15 \mathrm{~s} \text { with } \\
\text { gently agitation }\end{array}$ & $\begin{array}{l}\text { 4. Dry with absorbent paper, keeping } \\
\text { dentin moisture }\end{array}$ \\
\hline & & $\begin{array}{l}\text { 5. Gently air thin for } 5 \mathrm{~s} \text { to eva- } \\
\text { porate the solvent }\end{array}$ & $\begin{array}{l}\text { 5. Apply two consecutive coats of } \\
\text { Single Bond } 2 \text { for } 15 \mathrm{~s} \text { with gently } \\
\text { agitation }\end{array}$ \\
\hline & & 6. Light cure adhesive for $10 \mathrm{~s}$ & $\begin{array}{l}\text { 6. Gently air thin for } 5 \mathrm{~s} \text { to evaporate } \\
\text { the solvent }\end{array}$ \\
\hline & & $\begin{array}{l}\text { 7. Apply the silane on the pre- } \\
\text { viously ragged surface of resin } \\
\text { block }\end{array}$ & 7. Light cure adhesive for $10 \mathrm{~s}$ \\
\hline & & $\begin{array}{l}\text { 8. Mix cement for } 10 \mathrm{~s} \text { and apply } \\
\text { on silanized surface of resin } \\
\text { blocks }\end{array}$ & $\begin{array}{l}\text { 8. Apply the silane on the previously } \\
\text { ragged surface of resin block }\end{array}$ \\
\hline & & $\begin{array}{l}\text { 9. Wait } 3 \mathrm{~min} \text { and light cure each } \\
\text { surface/margin for } 40 \mathrm{~s}\end{array}$ & $\begin{array}{l}\text { 9. Mix cement for } 10 \mathrm{~s} \text { and apply on } \\
\text { silanazed surface of resin blocks } \\
\text { 10. Wait } 3 \text { min and light cure each } \\
\text { surface/margin for } 40 \mathrm{~s}\end{array}$ \\
\hline \multirow[t]{8}{*}{$\begin{array}{l}\text { RelyX U200 (3M/ESPE, } \\
\text { Seefeld, Germany) }\end{array}$} & \multirow{8}{*}{$\begin{array}{l}\text { RelyX } \mathbf{X}^{\mathbf{T M}} \text { U200: Silane treated glass powder, substituted dime- } \\
\text { thacrylate, 1-benzyl- } 5 \text {-phenyl-barbic-acid, calcium salt, 1,12- } \\
\text { dodecane dimethycrylate, sodium p-toluenesulfinate, silane } \\
\text { treated silica, calcium hydroxide }\end{array}$} & $\begin{array}{l}\text { 1. Apply the silane on the pre- } \\
\text { viously ragged surface of resin } \\
\text { block }\end{array}$ & $\begin{array}{l}\text { 1. Apply } 37 \% \mathrm{H}_{3} \mathrm{PO}_{4} \text { Gel (Condac } 37 \% / \\
\text { FGM, Joinville, SC, Brazil) for } 15 \mathrm{~s}\end{array}$ \\
\hline & & $\begin{array}{l}\text { 2.Mix cement for } 10 \mathrm{~s} \text { and apply } \\
\text { on silanized surface of resin } \\
\text { blocks }\end{array}$ & 2. Rinsing with air spray \\
\hline & & $\begin{array}{l}\text { 3.Wait } 3 \text { min and light cure each } \\
\text { surface/margin for } 20 \mathrm{~s}\end{array}$ & $\begin{array}{l}\text { 3. Apply } 5 \% \mathrm{NaOCl} \text { (Vetec, Rio de } \\
\text { Janeiro, RJ, Brazil) for } 2 \mathrm{~min}\end{array}$ \\
\hline & & & 4. Rinsing with air spray for $30 \mathrm{~s}$ \\
\hline & & & $\begin{array}{l}\text { 5. Dry with absorbent paper, keeping } \\
\text { dentin moisture }\end{array}$ \\
\hline & & & $\begin{array}{l}\text { 6. Apply the silane on the previously } \\
\text { ragged surface of resin block }\end{array}$ \\
\hline & & & $\begin{array}{l}\text { 7. Mix cement for } 10 \mathrm{~s} \text { and apply on } \\
\text { silanized surface of resin blocks }\end{array}$ \\
\hline & & & $\begin{array}{l}\text { 8. Wait } 3 \text { min and light cure each } \\
\text { surface/margin for } 20 \mathrm{~s}\end{array}$ \\
\hline
\end{tabular}

pretreatment with phosphoric acid can result in reduction of the bond strength since the exposition of collagen fibrils after dentin demineralization reduced the penetration of the cement $[18,19]$. The collagen removal after etching with phosphoric acid could be an option to eliminate this mechanical barrier and improve the penetration [20] and the chemical interactions between resin cements and the hydroxyapatite of the dentin [21], providing optimized results.

Some studies have shown that collagen removal has a beneficial effect in the cement-dentin adhesion $[19,22]$ but to the extent of our knowledge no experiments have been performed to evaluate this technique after aging under thermocycling. Therefore, this in vitro study examined the effect of deproteinization on the microtensile bond strength ( $\mu \mathrm{TBS}$ ) and nanoleakage (NL) between conventional and self-adhesive resin cements and dentin surfaces after $24 \mathrm{~h}$ or 20,000 thermocycles. The following hypotheses of study were tested: 1) the use of dentin deproteinization will not result in differences in the adhesive performance; 2) there is no difference between adhesive performance when a conventional and a self-adhesive resin cements was compared and; 3 ) thermocycles will not result in differences in the adhesive performance.

\section{Materials and methods}

\subsection{Tooth preparation}

Thirty-two freshly extracted human non-carious third molars were used in this study after obtaining the patients informed consent for their use, under a protocol approved by the Institution. The teeth were stored in $0.01 \%$ thymol solution at $4{ }^{\circ} \mathrm{C}$ for no more than 1 month. A flat dentin surface was exposed on each tooth after wet grinding of the occlusal enamel on \#100- and \# 400-grit SiC paper mounted in a polishing machine (Aropol 2VArotec SA, São Paulo, SP, Brazil). Dentin surfaces were exposed and inspected under $\times 80$ magnification to ensure that no enamel remnants were left (Leica DM 1000 Leica Microsystems GmbH-Wetzlar, Germany). The exposed dentin surfaces were further polished on wet \#600-grit silicon-carbide paper for $20 \mathrm{~s}$ to produce a standardized smear layer. After that, each tooth was individually fixed to a sectioning machine (Isomet 1000, Buehler Ltd. Lake Bluff, USA) and teeth roots were removed using a diamond disc under cooling, and to obtain dentin discs with $4 \mathrm{~mm}$ thick. 


\subsection{Restorative procedure}

Resin composite (Filtek Z100, shade A3-3M ESPE, Seefeld, Germany) blocks $\left(5.5 \times 5.5 \times 2.0 \mathrm{~mm}^{3}\right)$ of restorative materials were made with the aid of a two-piece matrix. The resin blocks were light activated for $80 \mathrm{~s}$ (40 s per side) with LED dental curing unit (DB -685; Dabi Atlante Ribeirão Preto/SP, Brazil). The restoration surface in contact with the dentin was roughened with a diamond point $30 \mu \mathrm{m}$ (FG 3098F, KG Sorensen, Cotia, SP, Brazil) $[22,23]$, and then submitted to an ultrasonic bath in distilled water for $10 \mathrm{~min}$. Before the cementation, the internal surface was silanized (Prosil, FGM, Joinville, SC, Brazil) following manufacturer's instructions. The blocks and teeth were randomly assigned using the Microsoft Excel randomization method.

RelyX ARC/Single Bond 2 (shade: A3, 3M ESPE, Seefeld, Germany) (conventional resin cement) or RelyX U200 (shade: A2, 3M ESPE, Seefeld, Germany) (self-adhesive resin cement) was used for luting the resin blocks to the dentin surface. In accordance with the strategy of cementation the specimens were distributed into four groups $(n=8)$ : RelyX ARC/Single Bond 2 (RAc) following the manufacturer's instructions (control), RelyX ARC/Single Bond 2 (RAd) after dentin deproteinization; RelyX U200 (RUc) following the manufacturer's instructions; RelyX U200 (RUd) after dentin deproteinization (Table 1). For the deproteinization, dentin surface was treated with $5 \%$ sodium hypochlorite $(\mathrm{NaOCl})$ (Vetec, Rio de Janeiro, RJ, Brazil) for $2 \mathrm{~min}$ and rinsed for $30 \mathrm{~s}$ [19,22,24,25]. The cementation was done following the manufacturer's instructions (Table 1). During luting procedure, the pressure exerted on the restoration was standardized at $20 \mathrm{~g} / \mathrm{mm}^{2}$.

\subsection{Specimens preparation and thermocycling}

After $24 \mathrm{~h}$, each restored tooth was longitudinally sectioned in both " $x$ " and " $y$ " directions, across the bonded interface, using a diamond blade saw under water cooling (Isomet 1000, Buehler Ltd., Lake Bluff, USA) to obtain sticks with cross-sectional areas of approximately $0.9 \mathrm{~mm}^{2}$.

Half of the sticks of each bonded-tooth were randomly subdivided into one of two subgroups to be tested under microtensile test: initial (test after $24 \mathrm{~h}$ in distilled water at $37^{\circ} \mathrm{C}$ ) and after thermocycling. For this procedure, the specimens were placed in a thermocycling machine (THE-1100 Thermocycler; SD Mechatronik Gmbh, Feldkirchen-Westerham, Germany) in distilled water baths for 20,000 cycles of $5-55{ }^{\circ} \mathrm{C}$ with a dwelling time of $60 \mathrm{~s}$ in each bath.

\subsection{Microtensile bond strength test}

The sticks were measured individually with digital caliper (Absolute Digimatic, Mitutoyo, Tokyo, Japan) and subjected in a tensile force in a universal testing machine (Model 4440, Instron Corp., Canton, MA, USA) at crosshead speed of $1 \mathrm{~mm} / \mathrm{min}$.

The dentin side of the failed bonds was analyzed using stereoscopic light microscopy (Stemi 2000-C, Carl Zeiss Jena; Jena, Germany) at 80x magnification and was classified according to the failure mode as adhesive or mixed (M), cohesive in cement (CC), cohesive in dentin (CD) or cohesive in composite (CC). All sticks (including those prematurely failed) were included in the failure mode analysis.

\subsection{Nanoleakage evaluation (NL)}

Five bonded sticks from each group at each storage period were coated with two layers of nail varnish applied up to within $1 \mathrm{~mm}$ of the bonded interfaces. The bonded sticks were placed in the ammoniacal silver nitrate in darkness for $24 \mathrm{~h}$, rinsed thoroughly in distilled water, and immersed in photo developing solution for $8 \mathrm{~h}$ under a fluorescent light to reduce silver ions into metallic silver grains within voids along the bonded interface [20].

Specimens were mounted on aluminum stubs, polished with a 1000-grit SiC paper and 6, 3, 1 and $0.25 \mu \mathrm{m}$ diamond paste (Buehler Ltd, Lake Bluff, IL, USA). Then, they were ultrasonically cleaned, air dried and gold sputter coated (MED 010, Balzers Union, Balzers, Liechtenstein) for analysis in a scanning electron microscope (SEM) operated in the backscattered mode (LEO 435 VP, LEO Electron Microscopy Ltd., Cambridge, UK).

In order to standardize image acquisition, three pictures were taken of each specimen. The first picture was taken in the center of the bonded stick. The other two pictures were taken $0.3 \mathrm{~mm}$ to the left and right of the first one. As two bonded sticks per tooth were evaluated and a total of five teeth were used for each experimental condition, a total of 30 images were evaluated per group. A technician who was blinded to the experimental conditions under evaluation performed all acquisitions. The amount of nanoleakage within the adhesive and hybrid layer areas was only qualitatively evaluated.

\subsection{Statistical analysis}

The experimental unit in the current study was the hemi-tooth, since half of the tooth was tested initially and the other half was tested after thermocycling. The microtensile bond strength values of all sticks from the same hemi-tooth were averaged for statistical purposes. The microtensile bond strength (MPa) data, including the premature failures as $0 \mathrm{MPa}$, were subjected to three-way (type of cement, strategy of luting and time) repeated measures ANOVA and Tukey's post-hoc test at $\alpha=5 \%$. Also, the ratio between obtained specimens (OS) and lost specimens (LO) for different groups were evaluated by chi-square test $(\alpha=0.05)$.

\section{Results}

\subsection{Microtensile bond strength test}

The three-way ANOVA showed that the interaction was statistically significant $(p=0.001)$. The use of the dentin deproteinization significantly improved the bond strength for both cements tested $(p=0.01)$; however, only RUd maintained the bond strength values after the thermocycling $(p=0.25)$. For control groups (RAc and RUc) no statistical difference was found regardless of the aging by thermocycling $(p>0.68)$. The $\mu$ TBS means, standard deviation and number of specimens tested are shown in Tables 2 and 3 according to the factors of the study. The percentage of the obtained specimens (OS) and lost specimens (LO) are shown in Table 4.

After the thermocycling, only the RAd group showed a significant reduction of the bond strength values for $\mu$ TBS $(p=0.0001)$. However, it was observed significant amount of premature failures for three of the four groups after thermocycling (RAc, RUc and RAd; $p<0.01$ ).

Table 2

Mean microtensile bond strengths (MPa) and standard derivations (SD) for the groups, as well as, statistical analysis $\left({ }^{*}\right)$.

\begin{tabular}{llllll}
\hline & \multicolumn{3}{c}{ Control (c) } & & \multicolumn{2}{l}{ Deproteinized (d) } \\
\cline { 2 - 3 } \cline { 5 - 6 } \cline { 5 - 6 } & Immediately & Thermocycled & & Immediately & Thermocycled \\
\hline $\begin{array}{c}\text { RelyX ARC/Single } \\
\text { Bond 2 (RA) } \\
\text { RelyX U 200 (RU) }\end{array}$ & $10.97 \pm 2.9^{\mathrm{c}}$ & $11.59 \pm 3.7^{\mathrm{c}}$ & & $15.71 \pm 4.4^{\mathrm{b}}$ & $7.76 \pm 2.4^{\mathrm{d}}$ \\
\cline { 5 - 6 } & $11.68 \pm 3.4^{\mathrm{c}}$ & $11.20 \pm 3.3^{\mathrm{c}}$ & & $19.44 \pm 4.7^{\mathrm{a}}$ & $17.88 \pm 5.4^{\mathrm{a}, \mathrm{b}}$ \\
\hline
\end{tabular}

* Identical superscript letters indicate no significant difference $(p>0.05)$. 
Table 3

Obtained specimens (OS) X lost specimens (LO) in percentages, as well as, statistical analysis $\left({ }^{*}\right)$.

\begin{tabular}{|c|c|c|c|c|c|c|c|c|}
\hline & \multicolumn{4}{|c|}{ Control (c) } & \multicolumn{4}{|c|}{ Deproteinized (d) } \\
\hline & \multicolumn{2}{|c|}{ Immediately } & \multicolumn{2}{|c|}{ Thermocycled } & \multicolumn{2}{|c|}{ Immediately } & \multicolumn{2}{|c|}{ Thermocycled } \\
\hline & OS & LO & OS & LO & OS & LO & OS & LO \\
\hline $\begin{array}{l}\text { RelyX ARC/Single } \\
\text { Bond } 2 \text { (RA) }\end{array}$ & 51 & $\begin{array}{l}10 \\
(19 \%)^{a}\end{array}$ & 48 & $16(33 \%)$ & 39 & $\begin{array}{l}11 \\
(28 \%)^{a}\end{array}$ & 38 & $\begin{array}{l}20 \\
(52 \%)^{b}\end{array}$ \\
\hline RelyX U200 (RU) & 50 & $8(16 \%)$ & 51 & $20(39 \%)$ & 49 & $5(10 \%)$ & 52 & $\begin{array}{l}10 \\
(19 \%)^{a}\end{array}$ \\
\hline
\end{tabular}

* Identical superscript letters indicate no significant difference $(p>0.05)$.

The distribution of failure modes for each group is summarized in Table 4. RelyX ARC groups showed a high incidence of mixed failures, while RelyX U200 groups showed predominance of cohesive fractures within the resin cement, especially for the groups submitted to thermocycling procedures. Cohesive fractures within the dentin were not observed for none of the groups.

\subsection{Nanoleakage evaluation (NL)}

Representative backscattering SEM images of the adhesive interface produced in the all conditions tested can be seen in the Fig. 1. When dentin was deproteinized (RAd and RUd; Fig. 1C, D and $\mathrm{H}$ ), minimal silver nitrate deposition along the adhesive interface was observed in comparison to control groups (RAc and RUc; Fig. 1A, B, E and F). However, after thermocycling, the RAd group showed increasing of amount of silver nitrate (Fig. 1G).

\section{Discussion}

In accordance with the present results, dentin deproteinization improved the performance of the self-adhesive resin cement, resulting in rejection of the first hypothesis.

$\mathrm{NaOCl}$ is a nonspecific proteolytic agent that effectively removes organic components at room temperature [20]. It is capable of producing chemical alterations on the surface of demineralized dentin making it more similar to enamel (hydroxyapatite-rich) [5]. In order to improve adhesion between the dentin and resin materials concentrations of $10 \%$ applied for $1 \mathrm{~min}$ [26,27] and 5\% for 2 min [19,22,24,25] have been used. The most porous surface achieved after this pre-treatment could be responsible for adhesive interfaces with similar bond strength values to those obtained in enamel after etching with phosphoric acid [28], thereby allowing mechanical retention [29,30] and chemical interaction [31].

RelyX U200 self-adhesive cement contains phosphoric acidic methacrylates, 4-MET, which react with basic fillers in the cement and the calcium ions of the hydroxyapatite from tooth tissue promoting the bonding to dentin and enamel [2]. This acidic monomer has an ability to form strong ionic bond with calcium of enamel and dentin [32]. Thus, the bonding mechanism of selfadhesive resin cements to dentin is based on chemical reactions between dentin and resin cements while the bonding mechanism of conventional luting systems depends of the type of the bonding agent used in combination with this system [6]. After the removal of collagen achieved by $\mathrm{NaOCl}$ application, the mineral to matrix ratio at dentin surface increased and the smear layer was thinned due to dissolution of the collagen part [33,34] which can may optimize the maximum interaction between RelyX U200 luting agent and hydroxyapatite of dentin, improving the chemical reactions. This can explain the highest bond strength values and

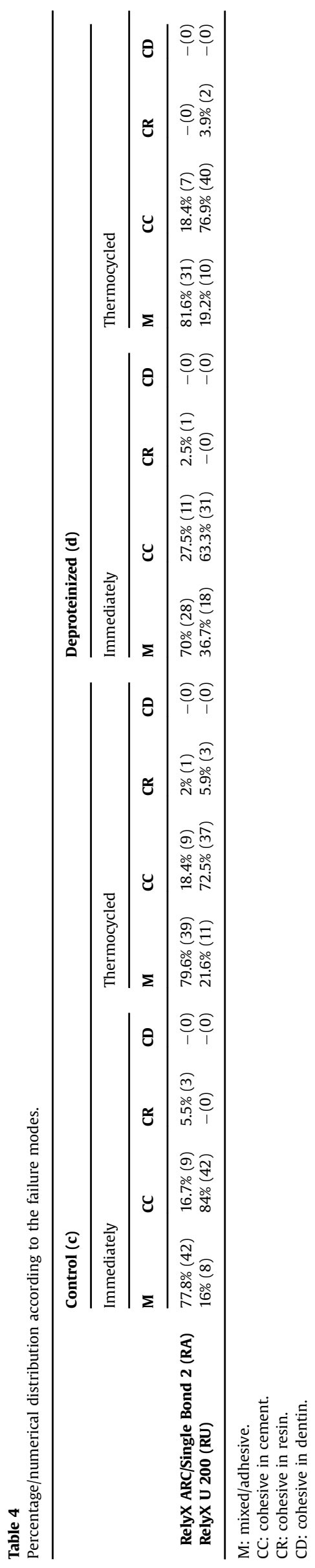


Control
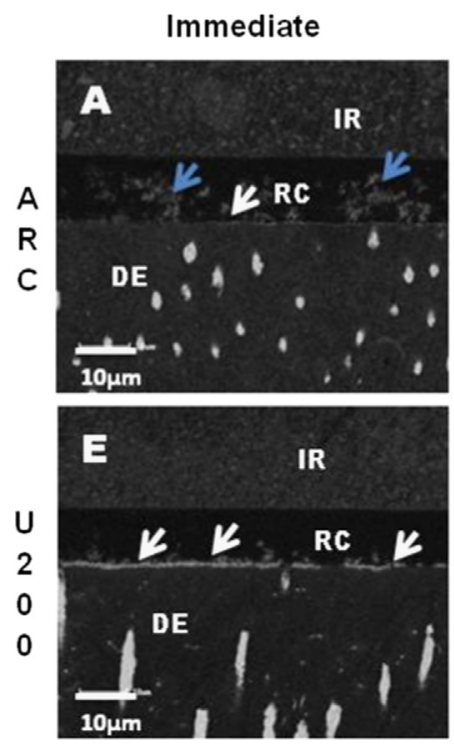

Termocycled
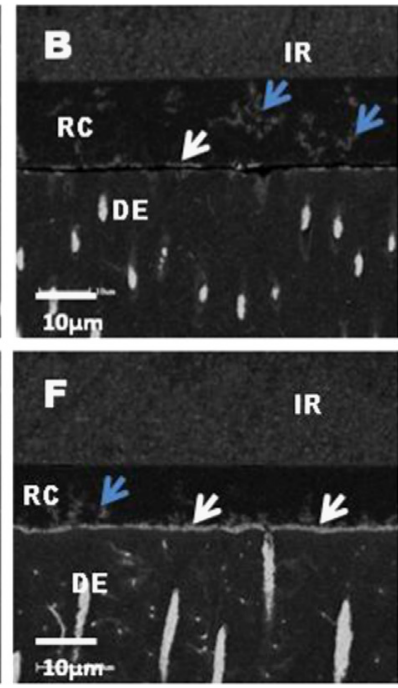

Desproteinized

Immediate
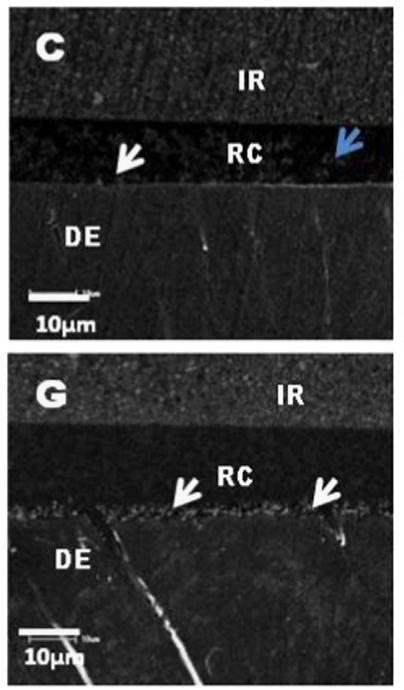

Termocycled
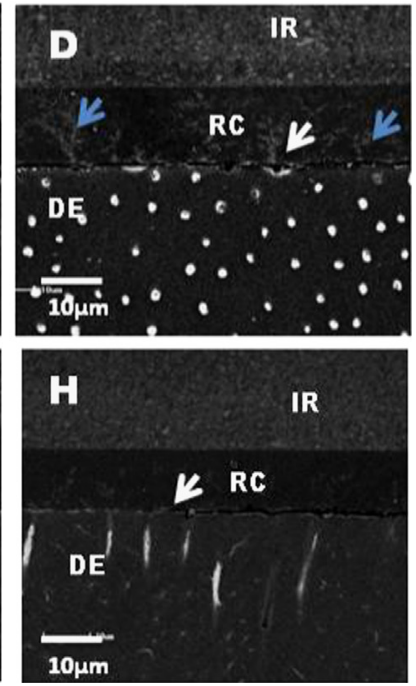

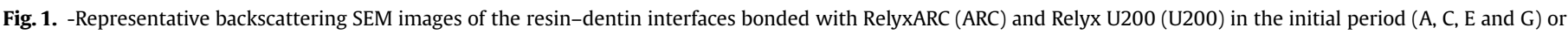

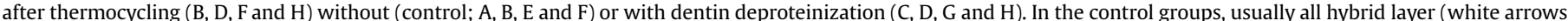

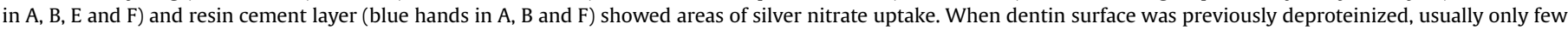

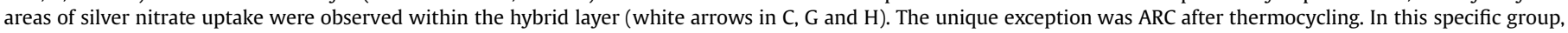
the nanoleakage occurred also inside the adhesive layer (blue hands in D). (IR=indirect restoration; $\mathrm{Rc}=\mathrm{resin}$ cement; and $\mathrm{De}=\mathrm{dentin}$ ).

lower nanoleakage pattern showed for RUd group when compared to RAd, which leads to reject the second null hypothesis.

The self-adhesive cements with their heavy filler load and high viscosity may exhibit limited infiltration into the exposed collagen layer [4]. However, for RelyX U200 a new rheology modifier to reduce the viscosity was added to the mixture and the processing of its filler particles was optimized as advocated by the manufacturer. The new rheology may have facilitated the penetration of the cement into the porosities and lateral branches created by $\mathrm{NaOCl}$ on the dentin, promoting a more intimate contact between the self-adhesive cement and the substrate.

The highest percentage of cohesive failures within resin cement for RelyX U200 groups suggests the bond strength of the cement/ dentin interface exceeded the cohesive strength of the cement pointing out for an improvement of the chemical reaction with hydroxyapatite and better penetration of resin monomers into the deproteinized substrate. When using RelyX ARC, failures involving the hybrid layer (mixed) were predominant suggesting frailty of the adhesive interface. The absence of cohesive failures within dentin suggests that this substrate did not become weaker after deproteinization.

The lower bond strength results and higher nanoleakage pattern obtained by RAd group compared to RUd group in the initial test might be due to the adhesive used (Single Bond 2). Previous reports stated that this adhesive is not capable of effectively filling the pores created by the sodium hypochlorite because its slow diffusion [35,36]. For etch-and-rinse adhesives, such as Single Bond 2, the hybrid layer represents the principal mechanism of adhesion [37-39]. Therefore, the presence of collagen is pivotal. Contrariwise, for self-adhesive resin cement containing acidic functional monomers, collagen is less important and its mechanism of adhesion relies principally on the chemical interaction as aforementioned [8].

After thermocycling, only the RAd group showed a significant reduction of the bond strength values. However, analyzing the ratio between obtained specimens (OS) and lost specimens (LO), it was observed significant increase of premature failure of sticks and the amount of nanoleakage inside the adhesive interface for three groups after thermocycling (RAc, RUc and RAd) in agreement with previous investigations [40]. It demonstrates that thermocycling had an effective detrimental effect for these groups. Only RUd group did not show any influence of the thermocycling on the adhesive performance, which points out for the possible benefits of the $\mathrm{NaOCl}$ pre-treatment when using the self-adhesive cement RelyX U200.

It is important to point out that the $\mathrm{NaOCl}$ treatment makes the technique less sensitive once there is no collagen on the dentin surface and it eliminates the critical clinical step of controlling the amount of dentin moisture before adhesive application. We highlight to the importance of it when cementing fibers post considering that is even more difficult to control the dentin moisture in the root canal.

Taking in account all the criteria evaluated, the dentin deproteinization had the most positive impact for the self-adhesive cement. If the improvement of the longevity and effectiveness of the adhesion is demonstrated in clinical investigations, the addition of this clinical step in restorative practice could be justified.

In conclusion, the deproteinization improved bond strength for both resin cements to dentin for initial test, but after thermocycling aging the preservation dentin-cement interface occurred only when the self-adhesive resin cement RelyX U200 was used.

\section{References}

[1] Tanoue N, Koishi Y, Atsuta M, Matsumura H. Properties of dual-curable luting composites polymerized with single and dual curing modes. J Oral Rehabil 2003;30(10):1015-21.

[2] Hikita K, Van Meerbeek B, Demunck J, Ikeda T, Van Landuyt K, Maida T, et al. Bonding effectiveness of adhesive luting agents to enamel and dentin. Dent Mater 2007;23(1):71-80.

[3] Aguiar TR, Francescantonio MD, Arrais CAG, Ambrosano GMB, Davanzo C, Giannini M. Influence of curing mode and time on degree of conversion of one conventional and two self-adhesive resin cements. Oper Dent 2010;35 (3):295-9.

[4] Arrais C, Rueggeberg F, Waller J, Degoes M, Giannini M. Effect of curing mode on the polymerization characteristics of dual-cured resin cement systems. J Dent 2008;36(6):418-26. 
[5] De Menezes M, Arrais C, Giannini M. Influence of light-activated and auto- and dual-polymerizing adhesive systems on bond strength of indirect composite resin to dentin. J Prosthet Dent 2006;96(2):115-21.

[6] De Munck J, Vargas M, Van Landuyt K, Hikita K, Lambrechts P, Van Meerbeek $\mathrm{B}$. Bonding of an auto-adhesive luting material to enamel and dentin. Dent Mater 2004;20(10):963-71.

[7] Cantoro A, Goracci C, Papacchini F, Mazzitelli C, Fadda GM, Ferrari M. Effect of procure temperature on the bonding potential of self-etch and self-adhesive resin cements. Dent Mater 2008;24(5):577-83.

[8] Monticelli F, Osorio R, Mazzitelli C, Ferrari M, Toledano M. Limited decalcification/diffusion of self-adhesive cements into dentin. J Dent Res 2008;87 (10):974-9.

[9] Viotti RG, Kasaz A, Pena AE, Alexandre RS, Arrais CAG, Reis AF. Microtensile bond strength of new self-adhesive agents and conventional multistep systems. J Prosthet Dent 2009;102(5):306-12.

[10] Abo-Hamar SE, Hiller KA, Jung H, Federlin M, Friedl KH, Schmalz G. Bond strength of a new universal self-adhesive resin luting cement to dentin and enamel. Clin Oral Investig 2005;9(3):161-7.

[11] Duarte S, Botta A, Meire M, Sadan A. Microtensile bond strengths and scanning electron microscopic evaluation of self-adhesive and self-etch resin cements to intact and etched enamel. J Prosthet Dent 2008;100(3):203-10.

[12] Gerth H, Dammaschke T, Zuchner H, Schafer E. Chemical analysis and bonding reaction of RelyX Unicem and Bifix composites - a comparative study. Dent Mater 2006;22(10):934-41.

[13] D'arcangelo C, De Angelis F, D'amario M, Zazzeroni S, Ciampoli C, Caputi S. The influence of luting systems on the microtensile bond strength of dentin to indirect resin-based composite and ceramic restorations. Oper Dent 2009;34 (3):328-36.

[14] Goracci C, Cury AH, Cantoro A, Papacchini F, Tay FR, Ferrari M. Microtensile bond strength and interfacial properties of self-etching and self-adhesive resin cements used to lute composite onlays under different seating forces. J Adhes Dent 2006;8(5):327-35.

[15] Yang B, Ludwig K, Adelung R, Kern M. Micro-tensile bond strength of three luting resins to regional dentin. Dent Mater 2006:22(1):45-56.

[16] Mazzitelli C, Monticelli F, Toledano M, Ferrari M, Osorio R. Dentin treatment effects on the bonding performance of self-adhesive resin cements. Eur J Oral Sci 2010;118(1):80-6.

[17] Pavan S, Santos PH, Berger S, Bedran-Russo AK. The effect of dentin pretreatment on the microtensile bond strength of self-adhesive resin cements. J Prosthet Dent 2010;104(4):258-64.

[18] Santos MJ, Bapoo H, Rizkalla AS, Santos GC. Effect of dentin-cleaning techniques on the shear bond strength of self-adhesive resin luting cement to dentin. Oper Dent 2011;36(5):512-20.

[19] Lisboa DS, Santos SV, Griza S, Rodrigues JL, Faria-e-Silva AL. Dentin deproteinization effect on bond strength of self-adhesive resin cements. Braz Oral Res 2013;27(1):73-5.

[20] Tay FR, Pashley DH, Suh BI, Carvalho RM, Itthagaruna A. Single-step adhesives are permeable membranes. J Dent 2002 2002;30(7-8):371-82.

[21] Toledano M, Osorio R, Perdigao J, Rosales JI, Thompson JY, Cabrerizo-Vilchez MA. Effect of acid etching and collagen removal on dentin wettability and roughness. J Biomed Mater Res 1999;47(2):198-203.

[22] De Souza FB, Delfino CS, Turbino ML, Braz R. Deproteinized dentin: a favorable substrate to self-bonding resin cements? J Biomed Mater Res Part B Appl Biomater 2011;98(2):387-94.
[23] Cotes C, Cardoso M, Melo RM, Valandro LF, Bottino MA. Effect of composite surface treatment and aging on the bond strength between a core build-up composite and a luting agent. J Appl Oral Sci 2015;23(1):71-8.

[24] De Souza FB, Silva CHV, Palma Dibb RG, Delfino CS, Beatrice LCS. Bonding performance of different adhesive systems to deproteinized dentin-microTBS and SEM. J Biomed Mater Res Part B Appl Biomater 2005;75(1):158-67.

[25] Fawzy AS, Amer MA, El-Askary FS. Sodium hypochlorite as dentin pretreatment for etch-and-rinse single-bottle and two-step self-etching adhesives: atomic force microscope and tensile bond strength evaluation. J Adhes Dent 2008;10(2):135-44.

[26] De Castro AK, Hara AT, Pimenta LA. Influence of collagen removal on shear bond strength of one-bottle adhesive systems in dentin. J Adhes Dent 2000;2 (4):271-7.

[27] Saboia VP, Pimenta LA, Ambrosano GM. Effect of collagen removal on microleakage of resin composite restorations. Oper Dent 2002;279(1):38-43.

[28] Wakabayashi Y, Kondou Y, Suzuki K, Yatami H, Yamashita A. Effect of dissolution of collagen on adhesion to dentin. Int J Prosthodont 1994:7(4):302-6

[29] Perdigão JM, Thompson JY, Osorio R, Toledano M, Rosales JI, Cabrerizo MA. An AFM/SEM study of acid-etched and deproteinized dentin in function of depth. J Dent Res 1998;77(supplement 2):809.

[30] Vargas MA, Cobb DS, Armstrong SR. Resin-dentin shear bond strength and interfacial ultrastructure with and without a hybrid layer. Oper Dent 1997;22 (4):159-66.

[31] Kanca J. Resin bonding to wet substrate. I Bond dentin Quintessence Int 1992;23(1):39-41.

[32] Yoshida Y, Nagakane K, Fukuda R, Nakayama Y, Okazaki M, Shintani H, et al Comparative study on adhesive performance of functional monomers. J Dent Res 2004;83(6):454-8

[33] Montes MA, de Goes MF, Sinhoreti MA. The in vitro morphological effects of some current pre-treatments on dentin surface: a SEM evaluation. Oper Dent 2005;30(2):201-12.

[34] Mountouris G, Silikas N, Eliades G. Effect of sodium hypochlorite treatment on the molecular composition and morphology of human coronal dentin. J Adhes Dent 2004:6(3):175-82.

[35] Prati C, Chersoni S, Pashley DH. Effect of removal of surface collagen fibril on resin-dentin bonding. Dent Mater 1999;15(5):323-31.

[36] Saboia VPA, Rodrigues AL. Pimenta LAF. Effect of collagen removal on shear bond strength of two single-bottle adhesive systems. Oper Dent 2000;25 (5):395-400.

[37] Nakabayashi N, Kojima K, Masuhara E. The promotion of adhesion by the infiltration of monomers into tooth substrates. J Biomed Mater Res 1982:16 (3):265-73.

[38] Barkmeier WW, Los SA, Triolo Jr. PT. Bond strengths and SEM evaluation of Clearfil Liner Bond 2. Am J Dent 1995;8(6):289-93.

[39] Yamazaki PCV, Bedran-Russo AKB, Pereira PNR. Importance of the hybrid laye on the bond strength of restorations subjected to cyclic loading. J Biomed Mater Res Part B: Appl Biomater 2008;84B(1):291-7.

[40] Bacchi A, Abuna G, Babbar A, Sinhoreti MA, Feitosa VP. Influence of 3-month simulated pulpal pressure on the microtensile bond strength of simplified resin luting systems. J Adhes Dent 2015;17(3):265-71. 